\title{
The effect of recombinant bovine somatotrophin on ovarian follicular growth and development in heifers
}

\author{
J. G. Gong ${ }^{1}$, T. A. Bramley ${ }^{2}$ and R. Webb ${ }^{1 *}$ \\ ${ }^{1}$ AFRC Institute of Animal Physiology and Genetics Research, Edinburgh Research Station, Roslin, \\ Midlothian EH25 9PS, UK; and Department of Obstetrics and Gynaecology, University of \\ Edinburgh, 37 Chalmers Street, Edinburgh EH3 9EW, UK
}

\begin{abstract}
The effects of recombinant bovine somatotrophin (BST) on the dynamics of ovarian follicular growth and development and peripheral insulin concentrations were investigated. Initially, studies were carried out in a population of Hereford $\times$ Friesian heifers to validate the ultrasound technique. In the first experiment, 12 heifers were injected daily with either $25 \mathrm{mg}$ BST or vehicle for two oestrous cycles, and the effects on follicular dynamics and peripheral insulin were determined. In a second experiment, 12 heifers were given a single injection of $10 \mathrm{ml}$ saline or $320 \mathrm{mg}$ BST in a sustained-release formulation to examine the temporal relationships between growth hormone $(\mathrm{GH})$, insulin-like growth factor-1 (IGF-1), insulin and the number of follicles. The validation studies demonstrated that small follicles $(<5 \mathrm{~mm}$ in diameter) could be clearly detected by real-time ultrasound, and that $75 \%$ (9 of 12) of heifers showed three waves of dominant follicle development during the oestrous cycle, whereas the remainder had only two waves. The changes in the numbers of follicles of the three size categories ( $<5 \mathrm{~mm}$, small; 5-10 mm, medium-sized and $>10 \mathrm{~mm}$, large) also displayed a wave pattern similar to that of the dominant follicle, with a marked reduction in the number of subordinate follicles as the dominant follicle grew and reached its maximum size. In Expt 1, BST treatment increased the number of small follicles and caused a rise in peripheral insulin concentrations $(P<0.01)$ throughout the treatment period. However, there was no effect of BST on the timing for the pattern of follicular waves during the oestrous cycle, nor on the number of medium-sized or large follicles at each follicular wave. In the second experiment, the temporal change in the number of small follicles following BST treatment was positively correlated with the changes in the peripheral IGF-I and insulin concentrations. IGF- 1 and insulin concentrations increased $48 \mathrm{~h}$ after BST injection, and the number of small follicles had increased $24 \mathrm{~h}$ later and remained higher during the period when peripheral IGF- 1 and insulin concentrations were high. These results demonstrate first, that the number of small follicles was reduced as the dominant follicle grew and reached its maximum size and second that BST treatment could enhance the recruitment of small follicles in heifers. This increase in the number of small follicles was positively correlated with peripheral IGF-I and insulin concentrations. Third, BST did not affect the turnover of follicular waves, nor the inhibitory action of the dominant follicle on its subordinate follicles. We conclude that BST affects the recruitment of small follicles by increasing peripheral concentrations of IGF-1, or of insulin or both concentrations. Moreover, the effect of BST on the small follicle population was not mediated through the mechanism(s) by which the dominant follicle inhibits subordinate follicles.
\end{abstract}

\section{Introduction}

Treatment of heifers with recombinant bovine somatotrophin (BST) has been shown to double the population of ovarian follicles $2-5 \mathrm{~mm}$ in diameter measured by gross dissection at slaughter (Gong et al., 1991). This effect did not appear to

${ }^{*}$ Correspondence and reprint requests.

Received 2 March 1992. be mediated through changes in circulating gonadotrophin concentrations or in numbers of ovarian gonadotrophin receptors. The underlying mechanism(s) remains unclear, although peripheral insulin-like growth factor-I (IGF-1) and growth hormone $(\mathrm{GH})$ concentrations were increased by BST treatment (Gong et al., 1991).

Since gross dissection allows follicular populations to be measured only at a single time point, we monitored the dynamic changes in ovarian follicular populations during BST 
treatment using daily ultrasound scanning to obtain a better understanding of the underlying mechanism(s). This approach should also allow the determination of the temporal relationships between the follicular population and peripheral $\mathrm{GH}$, IGF-1 and insulin concentrations, and help to overcome the high variability in ovarian follicular populations among animals (Rajakoski, 1960; Erickson, 1966) which may have biased the results obtained in the previous study (Gong et al., 1991) using gross dissection.

Real-time ultrasound has enabled the reliable determination of ovarian follicular growth patterns in cattle for follicles $>5 \mathrm{~mm}$ in diameter during the oestrous cycle (Pierson and Ginther, 1984; Savio et al., 1988; Sirois and Fortune, 1988; Knopf et al., 1989; Boland et al., 1990), and has shown that the growth of follicles during the oestrous cycle in cattle occurs in a wave pattern, i.e. the synchronous development of a group of follicles within which one follicle subsequently becomes dominant, whereas other cohort follicles (subordinate follicles) regress. However, the number of waves of dominant follicles per oestrous cycle in cattle reported by various groups differs. Savio et al. (1988), and Sirois and Fortune (1988) found that most animals had a pattern of three waves per oestrous cycle, whereas Knopf et al. (1989) and Driancourt et al. (1991) reported that most heifers in their studies had a two-wave pattern. These differences may be due to different breeds, strains of cattle or environment. Moreover, although it is generally accepted that the dominance of one follicle during the process of folliculogenesis in cattle may be associated with inhibition in the growth of other cohort follicles (Ireland, 1987; Pierson and Ginther, 1987a, 1988; Kastelic et al., 1990), the precise timing of the dominant follicle growth pattern in relation to the dynamics of follicles $<5 \mathrm{~mm}$ in diameter has not been investigated in detail.

The objectives of this study were: (1) to establish whether the number of small follicles ( $<5 \mathrm{~mm}$ in diameter) could be accurately determined by ultrasound and to investigate the temporal relationships between dominant and subordinate follicles during the oestrous cycle in our population of heifers; (2) to examine the effect of daily BST injections on ovarian follicular dynamics and peripheral insulin concentrations; and (3) to determine the temporal relationships between changes in GH, IGF-1 and insulin and changes in the number of small follicles following treatment with a single dose of BST in a sustained-release formulation.

\section{Materials and Methods}

\section{Animals}

Hereford $\times$ Friesian heifers, approximately $2-3$ years of age, were kept together in a large open shed under a natural photoperiod. Heifers were fed hay (dry matter: $874 \mathrm{~g} \mathrm{~kg}^{-1}$; crude protein: $84 \mathrm{~g} \mathrm{~kg}^{-1}$ dry matter; metabolizable energy: $8.4 \mathrm{MJ}$ $\mathrm{kg}^{-1}$ dry matter; digestibility: $54.3 \%$ ), twice daily, supplemented with concentrates. Fresh water was provided ad libitum. The body weights of all the heifers were monitored once a week and did not change significantly throughout the experimental periods. Oestrus was determined by observation (four times daily) for behavioural oestrus (standing heat), aided by a
KAMAR heatmount detector (Kamar Inc., Steamboat Springs, CO).

\section{Ultrasound examination}

The ovaries of heifers were examined using a real-time B-mode linear array ultrasound scanner (Aloka Echo Camera SSD-210 DX II) equipped with a $7.5 \mathrm{MHz}$ intrarectal probe (UST-5511I-7.5) (Aloka Co., Ltd, Japan). A flexible plastic rod was attached to the cable of the probe to enable its manipulation from outside the rectum. Each ovary was located and held in position with one hand while the probe was inserted into the rectum and placed directly on the top of the ovary. Results for each ovary were recorded on videotape for subsequent analysis. Diameters of follicles were determined using a computerized calliper device, taking the mean of two estimates at right angle planes. All follicles detected by this technique were divided into three size categories: $<5 \mathrm{~mm}$ (small), 5-10 mm (medium-sized) and $>10 \mathrm{~mm}$ (large) in diameter. Daily recordings enabled the changes in the growth of individual follicles $\geq 5 \mathrm{~mm}$ in diameter (medium-sized and large) to be studied. Although the numbers of small follicles could be assessed, it was not possible to follow their daily growth patterns.

The ovaries of 12 heifers were scanned prior to slaughter to validate the ultrasound procedure. Ovaries were collected and all follicles $\geq 2 \mathrm{~mm}$ in diameter were dissected. The mean ( \pm SEM) diameter of the largest follicles on a pair of ovaries was $12.1 \pm 0.7 \mathrm{~mm}$ after dissection versus $11.9 \pm 0.7 \mathrm{~mm}$ by ultrasound $(r=0.89, P<0.01)$. All large follicles at dissection were detected by ultrasound $(r=1.0, P<0.01$ ). There was a highly significant correlation $(r=0.92, P<0.01)$ between the number of medium-sized follicles detected by ultrasound and that at gross dissection, and $44 \%$ of follicles at dissection were detected by ultrasound. For small follicles there was also a highly significant correlation $(r=0.94, P<0.01)$ between the numbers of follicles detected by ultrasound and by gross dissection: $19 \%$ of follicles at dissection were detected by ultrasound.

Oestrous cycles of 12 heifers were synchronized by two i.m. injections, given 12 days apart, of $500 \mu \mathrm{g}$ synthetic prostaglandin (Estrumate: Coopers Animal Health Ltd, Crewe, Cheshire) to monitor follicular dynamics in our population of cattle. After the second injection of prostaglandin, animals were scanned daily for approximately 30 days.

The following definitions have been used (see also Ireland, 1987; Savio et al., 1988) to describe the pattern of follicular growth. (1) Follicular wave: the synchronous recruitment and growth of a group of follicles from which a single follicle usually develops to a diameter of $>10 \mathrm{~mm}$ (dominant follicle) while other cohort follicles (subordinate follicles) regress; (2) the onset of a follicular wave: the first day a follicle, which subsequently becomes a dominant follicle, can be identified.

\section{Experimental procedures}

Experiment 1. Oestrous cycles of 12 heifers were synchronized as described above. Heifers were assigned randomly into two groups of six animals (BST group and control group). From day 7 (day of oestrus = day 0 ) of the first oestrous cycle, 
all animals in the BST group were injected subcutaneously with a sterile preparation of $25 \mathrm{mg}$ recombinant BST daily (Somidobove: Eli Lilly \& Co., Indianapolis, IN; I $\mathrm{mg} \mathrm{ml}^{-1}$ in a vehicle containing $0.15 \mathrm{~mol} \mathrm{NaCl} \mathrm{l^{-1 }}, 0.025 \mathrm{~mol} \mathrm{NaHCO}_{3} \mathrm{l}^{-1}$ and $0.025 \mathrm{~mol}$ $\mathrm{Na}_{2} \mathrm{CO}_{3} \mathrm{l}^{-1}, \mathrm{pH}$ 9.6), for two oestrous cycles (43 days). Control animals received $25 \mathrm{ml}$ of vehicle for the same period. Blood samples were collected by jugular venepuncture three times a week from day 3 of the first oestrous cycle until the end of the experiment. Serum was stored at $-20^{\circ} \mathrm{C}$ for the subsequent measurement of peripheral GH, IGF-I, insulin and progesterone concentrations. All heifers were scanned daily from day 1 of the first oestrous cycle until the end of the experiment.

Experiment 2. Oestrous cycles of a second batch of 12 heifers were synchronized as described previously. Heifers were then assigned randomly to two groups of 6 . On day 7 of the oestrous cycle, one group was injected subcutaneously with $320 \mathrm{mg}$ Somidobove in a sustained-release formulation (Eli Lilly \& Co., Indianapolis, IN), whereas the other group received $10 \mathrm{ml}$ of saline. All heifers were scanned daily from day 6 of the oestrous cycle until 3 days after ovulation, as determined by ultrasound scanning. Daily blood samples were collected, by jugular venepuncture throughout the experimental period, and serum was stored at $-20^{\circ} \mathrm{C}$ for the subsequent measurement of peripheral GH, IGF-I, insulin and progesterone concentrations.

\section{Hormone assays}

Progesterone. Concentrations of progesterone in peripheral serum were determined using a radioimmunoassay described by Corrie et al. (1981), and Price and Webb (1988) as modified for a non-extraction procedure by Law (1991). The minimum detectable concentration was $0.14 \mathrm{ng} \mathrm{ml}^{-1}$. The inter- and intraassay coefficients of variation $(\mathrm{CV})$ were 4.4 and $8.3 \%$, respectively.

IGF-1. Serum IGF-1 concentrations were measured by a radioimmunoassay described by Armstrong et al. (1990) and Gong et al. (1991). The sensitivity of the assay was $19.8 \mathrm{ng} \mathrm{ml}^{-1}$ and the inter-assay and intra-assay CVs were 9.8 and $6.2 \%$, respectively.

bGH. Serum bGH concentrations were determined by a radioimmunoassay as described by Hart et al. (1975) and modified by Lovendahl et al. (1991) and Gong et al. (1991). The sensitivity of the assay was $1.07 \mathrm{ng} \mathrm{ml}^{-1}$. The inter-assay CV was $10.4 \%$ and the intra-assay CV was $7.4 \%$.

Insulin. Serum insulin concentrations were measured by a radioimmunoassay described by Osmond et al. (1981) with slight modification. The crossreactions of IGF-1, IGF-2 and GH in this assay were all $<0.001 \%$. The sensitivity of the assay was $0.08 \mathrm{ng} \mathrm{ml}^{-1}$ and the inter-assay and intra-assay CVs were 9.2 and $5.7 \%$, respectively.

\section{Statistical analyses}

Data are presented as means \pm SEM. Daily changes in diameter for all the follicles that could be followed by ultrasound for at least two consecutive days were plotted over each oestrous cycle and for each animal to determine the wave pattern of follicular development. Daily change in follicle numbers for the three size categories of follicle (small, mediumsized and large) during oestrous cycles was determined. Temporal relationships between the dominant follicle and changes in the number of follicles for all three size categories during each follicular wave were determined for individual heifers. The duration of the follicular and luteal phases for each oestrous cycle was measured by defining the beginning of the luteal and follicular phases by a progesterone concentration above or below $1 \mathrm{ng}$ $\mathrm{ml}^{-\mathrm{I}}$, respectively. Differences in duration of oestrous cycle and in the duration of the luteal and follicular phases between heifers with three follicular waves per oestrous cycle and heifers with two waves were tested statistically by Student's $t$ test. Statistical differences $(P<0.05)$ between the two treatment groups in the number of follicles and temporal changes in hormone concentrations were analysed separately before and after the start of BST treatment by split-plot ANOVA for repeated measures. The main effects included treatment, day and the interaction of treatment by day. The effect of BST treatment on the number of follicular waves per oestrous cycle was analysed by $\chi^{2}$ test. Correlations between mean follicle numbers and GH, IGF-1 and insulin concentrations throughout the treatment period were determined by regression analysis.

\section{Results}

\section{Validation of real-time ultrasound measurements}

A comparison between ultrasound measurements and gross dissection was made for the numbers of follicles in three size categories (small, medium-sized and large) and diameter of the largest follicle in 12 heifers. In agreement with previous studies (Quirk et al., 1986; Pierson and Ginther, 1987b; Pieterse et al., 1990; Driancourt et al., 1991), there was a highly significant correlation $(P<0.01)$ between the two techniques for all the parameters studied. All large follicles, approximately $44 \%$ of medium-sized follicles and 19\% of small follicles present at dissection were detected by ultrasound. This result agrees with the report by Pieterse et al. (1990), who found that $34 \%$ of medium-sized follicles and $96 \%$ of large follicles identified at dissection could be detected by ultrasound.

In our validation study, 9 of 12 heifers $(75 \%)$ displayed three waves of dominant follicle growth (Fig. I) during the oestrous cycle, whereas the remaining three heifers had two waves. For the nine heifers with a three-wave cycle, the first, second and third waves were initiated on days $1.7 \pm 0.2,9.1 \pm 0.8$ and $15.8 \pm 1.1$ (day $0=$ day of oestrus), respectively, whereas in the three heifers with a two-wave pattern, the first and second waves started on days $1.3 \pm 0.5$ and $10.0 \pm 1.0$, respectively. Daily changes during the oestrous cycle in the mean number of follicles for all the three size categories (small, medium-sized and large) also displayed a wave pattern similar to that of the dominant follicle. As the dominant follicle grew and reached its maximum diameter there was a marked reduction in the number of small and medium-sized follicles. The wave patterns for the three size categories of follicles were highly synchronized; there was an increase in the number of follicles occurring first in smail follicles, followed by medium-sized follicles and finally large 


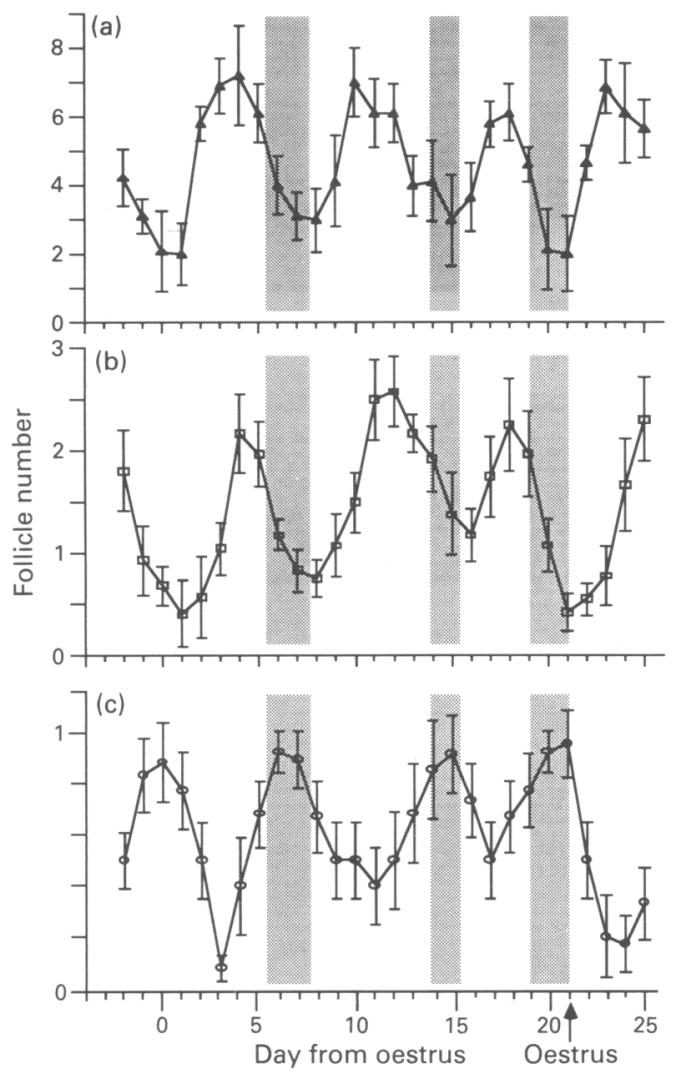

Fig. 1. Daily changes throughout the oestrous cycle in the mean ( \pm SEM) number of follicles: (a) $<5 \mathrm{~mm}$, (b) $5-10 \mathrm{~mm}$ and (c) $>10 \mathrm{~mm}$ in diameter in heifers $(n=9)$ having three waves of dominant follicle growth and development. The period (mean day \pm SEM) when the dominant follicles reached their maximum size is shown by the hatched boxes. Oestrous cycles of heifers were synchronized by two i.m. injections, given 12 days apart, of $0.5 \mathrm{mg}$ synthetic prostaglandin (PG). After the second PG injection, heifers were scanned daily for approximately 30 days. Ovulation occurred approximately $24 \mathrm{~h}$ after the detection of oestrus as indicated.

Table 1. Temporal relationships between wave patterns for the number of ovarian follicles of different sizes during the oestrous cycle in heifers

Day $^{\mathrm{a}}$ with the peak number of follicles

\begin{tabular}{lcccc} 
Wave pattern & $\begin{array}{c}<5 \mathrm{~mm} \\
\text { diameter }\end{array}$ & $\begin{array}{c}5-10 \mathrm{~mm} \\
\text { diameter }\end{array}$ & $\begin{array}{c}>10 \mathrm{~mm} \\
\text { diameter }\end{array}$ \\
\hline 3 waves & wave 1 & $2-5$ & $3-5$ & $6-9$ \\
$(n=9)$ & wave 2 & $10-12$ & $11-13$ & $14-15$ \\
& wave 3 & $16-18$ & $17-19$ & $20-22$ \\
2 waves & wave 1 & $2-5$ & $3-5$ & $6-10$ \\
$(n=3)$ & wave 2 & $11-13$ & $11-15$ & $15-21$ \\
\hline
\end{tabular}

${ }^{2}$ Day $0=$ day of oestrus.

$n=$ number of heifers.

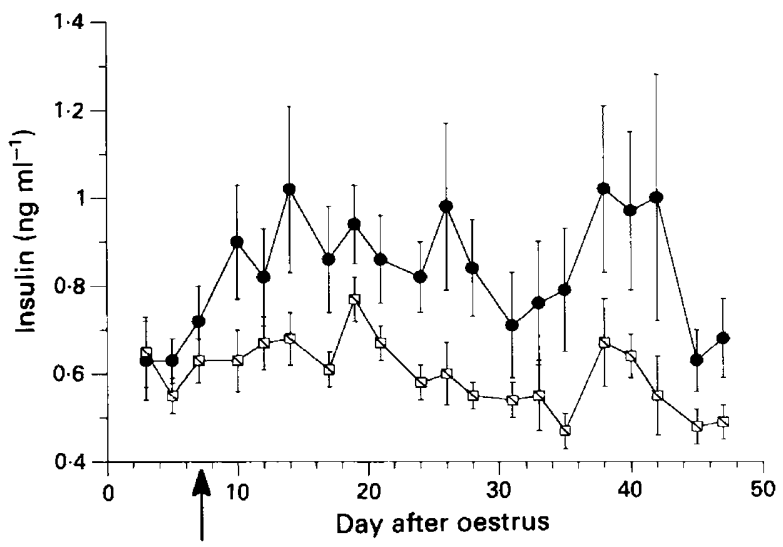

Fig. 2. Mean ( \pm SEM) concentrations of insulin before and after the start of daily injections of either bovine somatotrophin (BST) or vehicle ( $n=6$ per group). Heifers were injected daily with (O) $25 \mathrm{mg}$ BST or ( $\square$ ) vehicle from day 7 of the oestrous cycle for approximately two oestrous cycles. Day 0 represents the day of oestrus following the prostaglandin injection. The arrow indicates start of daily BST or vehicle treatment.

follicles (Fig. 1; Table 1). There was no significant difference in mean oestrous cycle duration for heifers having three (21.4 \pm 0.9 days) or two (20.3 \pm 0.6 days) follicular waves.

Experiment 1: Effect of BST on follicular growth patterns and peripheral insulin

Peripheral GH, IGF-1 and insulin concentrations. Before the start of BST treatment, the peripheral GH and IGF-1 concentrations of the two treatment groups were not different $\left(22.15 \pm 2.96\right.$ and $151.89 \pm 8.76 \mathrm{ng} \mathrm{ml}^{-1}$ and $23.43 \pm 3.12$ and $158.74 \pm 9.43 \mathrm{ng} \mathrm{ml}^{-\top}$, respectively, for the control and BST-treated group; effect of treatment, $P>0.05$; effect of treatment by day, $P>0.05$ ). Both peripheral GH and peripheral IGF-I concentrations for the BST-treated group had increased by 2 days after the start of BST injection and were significantly (effect of treatment, $P<0.01$; effect of treatment by day, $P>0.05)$ high $\left(37.44 \pm 2.31 \mathrm{ng} \mathrm{ml}^{-1}\right.$ for $\mathrm{GH}$ and $231.08 \pm$ $16.76 \mathrm{ng} \mathrm{ml}^{-1}$ for IGF-1) throughout the treatment period compared with the control group $\left(23.34 \pm 1.86 \mathrm{ng} \mathrm{ml}^{-1}\right.$ for $\mathrm{GH}$ and $153.87 \pm 10.89 \mathrm{ng} \mathrm{ml}^{-1}$ for IGF-1).

BST treatment significantly $(P<0.01)$ increased peripheral concentrations of insulin throughout the treatment period (Fig. 2).

Pafterns of follicular growth and number of follicles and ovulations. BST treatment did not alter the number of ovulations. Two of the BST-treated heifers and one of the control heifers displayed a two-wave pattern of follicular development during the oestrous cycle, whereas the remainder had three waves per oestrous cycle. Within each animal, the number of follicular waves per oestrous cycle for all heifers was consistent over the two oestrous cycles. All the characteristics of follicular dynamics (the starting day of each wave, duration of the oestrous cycle, wave pattern in follicle number and relationship between the dominant follicle and its subordinate follicles) were 


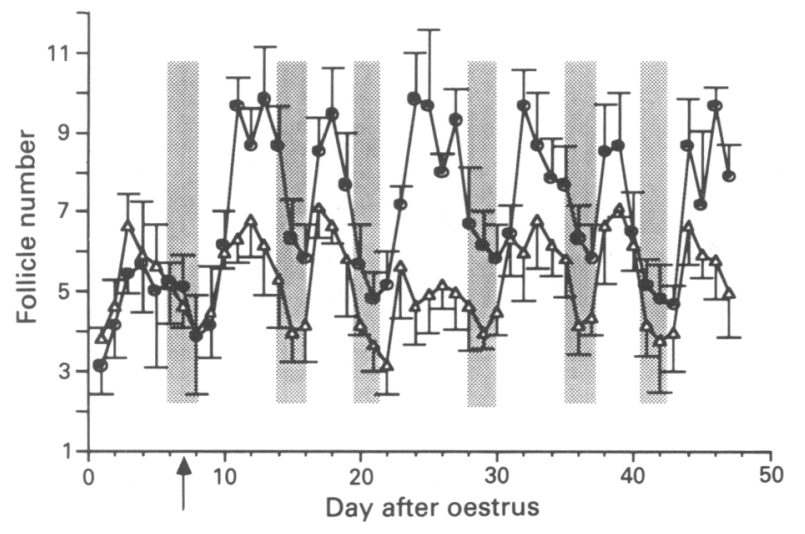

Fig. 3. Mean ( \pm SEM) number of follicles $<5 \mathrm{~mm}$ in diameter before and after the start of daily injections of either $(0)$ bovine somatotrophin (BST) or $(\triangle)$ vehicle ( $n=6$ per group). All animals with either two or three waves of dominant follicles have been included in the figure. Heifers were injected daily with $25 \mathrm{mg}$ BST or vehicle from day 7 of the oestrous cycle for approximately two oestrous cycles. The arrow indicates start of daily BST or vehicle injection. The period (mean day $\pm \operatorname{SEM}, n=12$ as there was no difference in this parameter between the two groups) when the dominant follicles reached their maximum size is shown by the hatched boxes.

similar to those described in Fig. 1 and Table 1. Although there was no difference between the two treatment groups before the start of the BST injections (effect of treatment, $P>0.05$; effect of treatment by day, $P>0.05$ ), BST-treated heifers had significantly more small follicles (effect of treatment, $P<0.01$ ) throughout the treatment period (Fig. 3). Moreover, the wave pattern for small follicles was unaffected by BST treatment. There was no interaction between treatment and day $(P>0.05)$, but the effect of day for the number of small follicles was significant $(P<0.01)$. There was no effect of BST treatment on either the number or the wave pattern for the number of medium-sized and large follicles (effect of treatment, $P>0.05$; effect of treatment by day, $P>0.05$ ) (Fig. 4).

The increase in the number of small follicles could be detected approximately $24 \mathrm{~h}$ after the rise in peripheral GH, IGF-1 and insulin concentrations. There was a significant correlation between the overall mean number of small follicles and mean $\mathrm{GH}(r=0.64, P<0.05)$, mean IGF-1 $(r=0.74, P<0.01)$ and mean insulin $(r=0.73, P<0.01)$ concentrations throughout the experimental period.

On the basis of peripheral progesterone concentrations, the duration of both the luteal and follicular phases of the oestrous cycle for heifers with three follicular waves $(16.3 \pm 0.6$ and $4.8 \pm 0.4$ days, respectively) were significantly different $(P<0.05)$ from heifers with two follicular waves $(13.9 \pm 0.9$ and $6.9 \pm 0.9$ days, respectively).

Experiment 2: Temporal relationship between GH, IGF-1, insulin and number of small follicles

Peripheral GH, IGF-I and insulin concentrations in BSTtreated heifers increased within 24,48 and $48 \mathrm{~h}$ after BST injection, respectively, and remained significantly high (effect of treatment, $P<0.01$ ) for approximately $7-8$ days compared

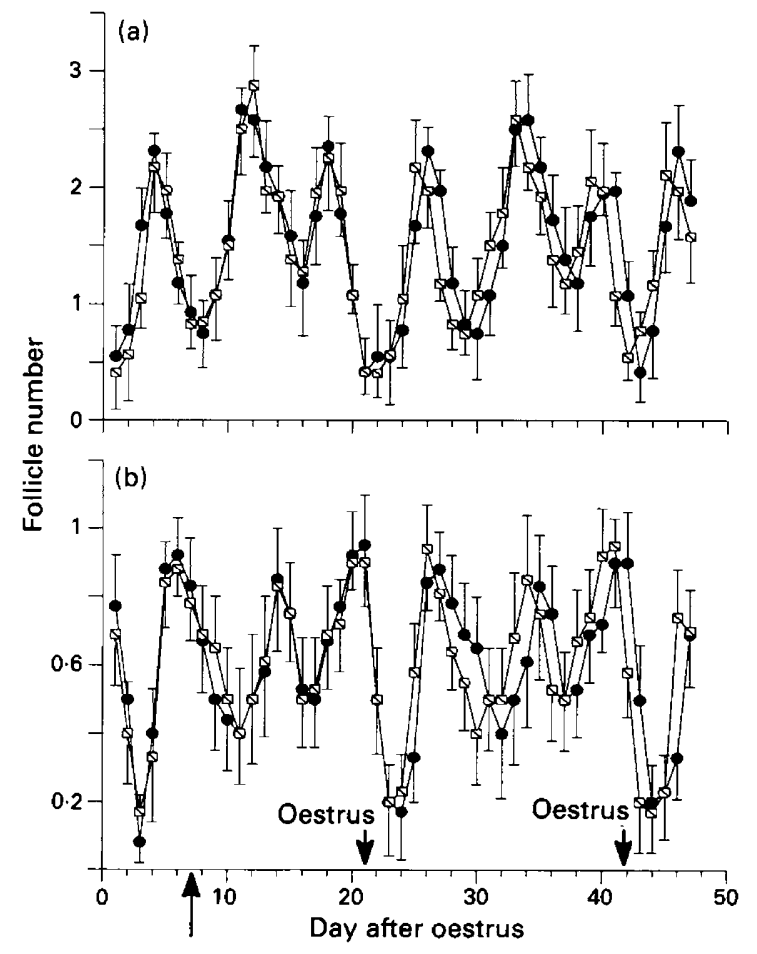

Fig. 4. The effect of daily bovine somatotrophin (BST) injection on the number and wave pattern for follicles (a) 5-10 $\mathrm{mm}$ and (b) $>10 \mathrm{~mm}$ in diameter throughout the experiment period ( $n=6$ heifers per group). Animals were injected daily with ( $25 \mathrm{mg}$ BST or $(\square)$ vehicle from day 7 of the oestrous cycle for approximately two oestrous cycles. The arrow $(\uparrow)$ indicates start of daily BST or vehicle treatment.

with control animals (Fig. 5). There was a significant effect of day $(P<0.05)$ and of treatment by day $(P<0.01)$. The number of small follicles increased within $24 \mathrm{~h}$ of the rise in IGF-I and insulin concentrations and remained higher throughout the period when peripheral IGF-1 and insulin concentrations were increased (effect of treatment, $P<0.01$; effect of day, $P<0.05$; effect of treatment by day, $P<0.01$ ). There was a significant correlation between the number of small follicles and both mean GH $(r=0.73, P<0.01)$, mean IGF-1 $(r=0.79$, $P<0.01)$ and mean insulin $(r=0.75, P<0.01)$ concentrations throughout the experiment. As in Expt 1 , all other parameters of ovarian follicular dynamics were unchanged by BST treatment (data not shown). There was no effect of BST on peripheral progesterone profiles (data not shown).

\section{Discussion}

This study has demonstrated first, that during the oestrous cycle there is a wave pattern for daily changes in numbers of follicles not only in medium-sized and large follicles, but also in small follicles. Furthermore, the growth of the dominant follicle was always associated with a marked reduction in the number of small and medium-sized subordinate follicles. Second, this work has extended our previous finding (Gong et al., 1991) that BST treatment can increase the population of small follicles in mature heifers, and shown that the effect of BST could be 

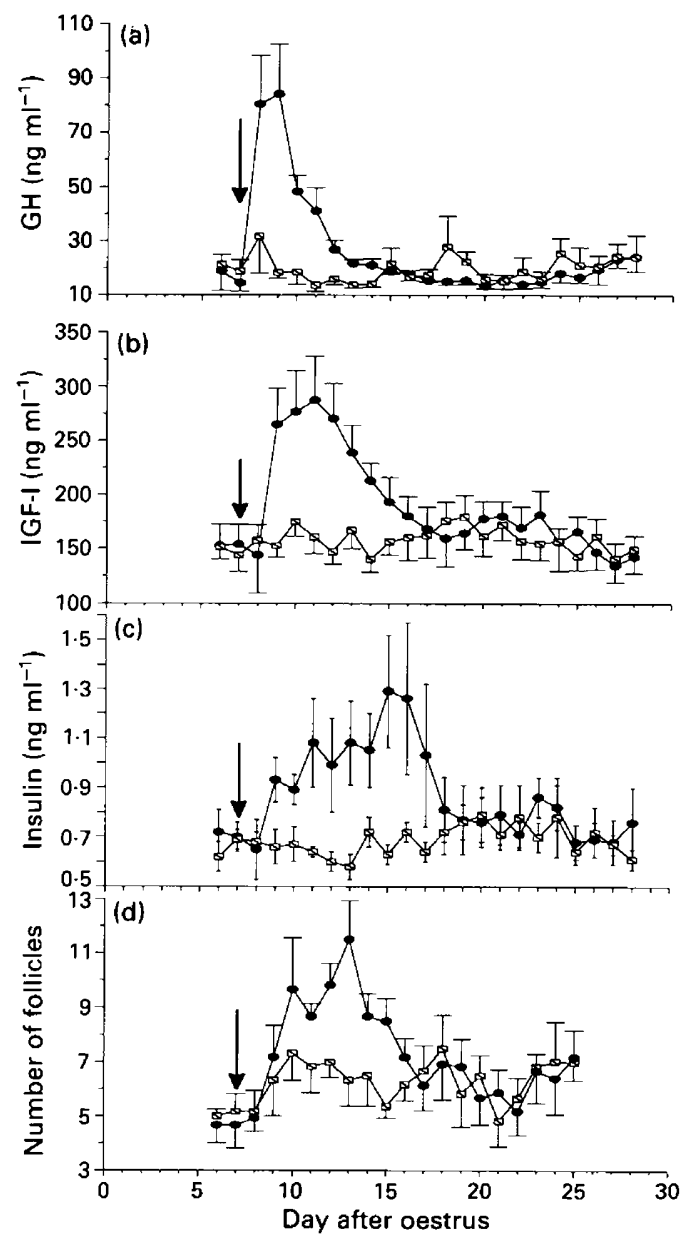

Fig. 5. Mean ( \pm SEM) (a) peripheral growth hormone $(\mathrm{GH})$ concentrations, (b) peripheral insulin-like growth factor (IGF-1) concentrations, (c) peripheral insulin concentrations and (d) number of follicles $<5 \mathrm{~mm}$ in diameter in $(\square)$ control and $(\bigcirc)$ BST-treated heifers $(n=6$ heifers per group) throughout Expt 2. Heifers were given a single injection of either BST ( $320 \mathrm{mg}$ in a sustained release formulation) or saline $(10 \mathrm{ml})$ on day 7 (arrow) of the oestrous cycle. Day 0 represents the day of oestrus following synchronization by two i.m. injections of $0.5 \mathrm{mg}$ synthetic prostaglandin, given 12 days apart. The day of BST or saline injection is indicated by the arrows.

detected within 3 days of the start of treatment. Moreover, the increase in the number of small follicles correlated with the increase in peripheral IGF-1 and insulin concentrations. Third, BST significantly increased the number of small follicles at all stages of the oestrous cycle, although the dynamics of follicular growth and the inhibitory effect of the dominant follicle on its subordinate follicles were not altered by BST treatment.

In agreement with previous studies using ultrasound (Savio et al., 1988; Sirois and Fortune, 1988; Knopf et al., 1989), our results confirm that ovarian follicular growth and development during the oestrous cycle in cattle is not continuous or independent of the stage of the cycle (Choudray et al., 1968; Donaldson and Hansel, 1968; Marion et al., 1968; Dufour et al., 1972), but occurs in a wave pattern (Rajakoski, 1960; Boland et al., 1990). The majority of the heifers in this study displayed three waves of dominant follicle growth and development per oestrous cycle, with the first, second and third waves beginning at approximately days 2,10 and 16 , respectively, in agreement with the reports by Savio et al. (1988) and Sirois and Fortune (1988). In contrast, Knopf et al. (1989) reported that nine out of ten heifers in their study had only two waves of dominant follicle development. In our study the remaining three out of 12 heifers showed two waves of dominant follicles, with characteristics similar to those reported by Knopf et al. (1989). There was no difference in duration of the oestrous cycle between heifers with a three-wave pattern and heifers with a two-wave pattern, in contrast to the reports of Knopf et al. (1989), Sirois and Fortune (1988) and Ginther et al. (1989). However, there was a suggestion that the duration of the luteal phase was shorter (whereas the duration of the follicular phase was longer) in heifers with two waves of follicular development compared with heifers with three waves.

This study clearly demonstrates that there are sequential changes throughout the oestrous cycle in the number of all follicles detected by ultrasound, including those $<5 \mathrm{~mm}$ in diameter, which occur in a wave pattern similar to the turnover of the dominant follicle. During each wave, an increase occurs first in the number of small follicles, followed by the mediumsized follicles and finally the large follicles. These data confirm and extend the results of Driancourt et al. (1991), since this timing relationship was observed by them only in the first wave of follicular growth during the oestrous cycle. These results also support previous hypotheses regarding the process of folliculogenesis (diZerega et al., 1980; Hodgen et al., 1985; Ireland and Roche, 1987) which suggest that folliculogenesis involves three consecutive phases, i.e. follicle recruitment, follicle selection and follicular dominance. Our results have demonstrated that the growth of the dominant follicle in each wave was associated consistently with a marked reduction not only in the number and growth of medium-sized subordinate follicles, but also in the number of small subordinate follicles. Whether this was due to an inhibition in recruitment, suppression of growth or an increase in the atresia rate of these small follicles could not be assessed. Inhibition of follicle growth, increase in rate of atresia or both factors seem likely, as the recruitment of small follicles into the growing pool has been suggested to be a continuous process (Peters et al., 1975; Ireland, 1987). Furthermore, it would appear that the regression of the dominant follicle was necessary for the initiation of the next dominant follicle growth wave during the oestrous cycle (Table 1 ), providing direct evidence to support the inhibitory effect ('dominance') of dominant follicles on subordinate follicles in both ovaries (Ireland, 1987; Pierson and Ginther, 1987a, 1988; Kastelic et al., 1990).

These studies have clearly demonstrated that BST treatment increased the population of small follicles in mature heifers within 3 days of the start of treatment. In Expt 2, within $24 \mathrm{~h}$ of BST injection, peripheral GH concentrations increased, followed within $24 \mathrm{~h}$ by a rise in peripheral IGF-I concentrations, and finally by an increase in the number of small follicles $24 \mathrm{~h}$ later. This increase in the number of small follicles was sustained throughout the period when peripheral IGF-1 concentrations were high, even when peripheral GH concentrations had returned to control values, suggesting that the effects of BST on the number of small follicles were mediated through increased peripheral IGF-1 concentrations. Indeed, IGF-1 is a wellaccepted intraovarian regulator of ovarian function (Adashi 
et al., 1985). However, a direct effect of BST cannot yet be excluded (Gong et al., 1991).

In contrast to the view that BST administration usually has no effect on serum insulin concentration in lactating animals (Vernon, 1990), BST treatment in our studies significantly increased peripheral insulin concentrations throughout the treatment period. Since it has also been suggested that insulin plays a role in the control of ovarian function (Savion et al,, 1981; Adashi et al., 1985; Poretsky and Kalin, 1987; Webb and McBride, 1991), insulin may also be involved in the effects of BST on small follicles. Indeed, like GH and IGF-1, mean insulin concentrations were significantly correlated with the number of small follicles in both experiments, and profiles of peripheral insulin concentrations were similar to those of IGF-1. In a recent study, bovine GH, when given together with insulin, stimulated bovine granulosa cell proliferation and steroidogenesis in vitro (Langhout ef al., 1991). We have also demonstrated that bovine insulin, at concentrations similar to those achieved in our present in vivo studies, stimulated the proliferation of cultured bovine granulosa cells alone or in combination with FSH (J. Gong, T. Bramley, D. McBride and R. Webb, unpublished).

Although the wave pattern of follicular growth was unchanged by BST treatment, the increase in numbers of small follicles was maintained throughout the whole of the treatment period, even when the dominant follicle was at its maximum diameter and the growth of the subordinate follicles was suppressed. BST treatment therefore increased the number of small follicles probably by enhancing the recruitment of these small follicles, rather than by increasing the growth rate or reducing the rate of atresia, although this will require further investigation. Our results also demonstrated that the mechanism(s) by which BST enhances the recruitment of small follicles is unlikely to be related to the mechanism(s) by which the dominant follicle inhibits subordinate follicles, since the dynamics of follicular growth and development were unaffected by BST treatment.

In agreement with our previous study using daily BST injection (Gong et al., 1991), a single dose of $320 \mathrm{mg}$ BST in a sustained release formulation did not affect peripheral progesterone concentrations. This contrasts with studies of Gallo and Block (1989) and Schemm et al. (1990), who found significantly higher plasma progesterone concentrations in lactating cows treated with BST.

In conclusion, our results support the hypothesis that the dominant follicle inhibits the growth of its subordinate follicles. The increase in the number of small follicles induced by BST treatment in heifers seems to result from an enhancement in follicle recruitment, possibly through increased peripheral IGF-1 or insulin concentrations, but does not appear to be mediated through the mechanism(s) by which the dominant follicle inhibits subordinate follicles.

J. G. Gong is sponsored by the Sino-British Friendship Scholarship Scheme. We thank J. Wilkinson of Eli Lilly \& Co. for providing the BST for this study and M. Ritchie, M. Thomson, W. Ritchie, B. Wilson, H. Bowran, D. McGavin, B. Seawright and G. Davidson for assistance with and care of the animals. We also thank $\mathrm{C}$. Goddard and P. Lovendahl for providing reagents for the IGF-1 and GH radioimmunoassays, respectively, and A. J. Springbett for advice on statistical analysis of data.

\section{References}

Adashi EY, Resnick CE, D'Ercole AJ, Svoboda ME and Van Wyk JJ (1985) Insulinlike growth factors as intraovarian regulators of granulosa cell growth and function Endocrine Reviews 6 400-420

Armstrong DG, Duclos MJ and Goddard C $(1990)$ Biological activity of insulin-like growth factor-I purified from chicken serum Domestic Animal Endocrinology 7 383-393

Boland MP, Murphy MG and Roche JF (1990) The use of ultrasound to monitor ovarian function in farm animals Agricultural Biotechnology News and Information 284 1-844

Choudray JB, Gier HT and Marion GB (1968) Cyclic changes in bovine vesicular follicles Journal of Animal Science 27 468-471

Corrie JET, Hunter WM and Macpherson JS (1981) A strategy for radioimmunoassay of plasma progesterone with the use of a homologous site ${ }^{125}$ I-labelled radioligand Clinical Chemistry 27 594-599

diZerega GS, Marut EL, Turner CK and Hodgen GD (1980) Asymmetrical ovarian function during recruitment and selection of the dominant follicle in menstrual cycle of the rhesus monkey Joumal of Clinical Endocrinology and Metabolism 51 698-701

Donaldson L and Hansel W (1968) Cystic corpora lutea and normal and cystic Graafian follicles in the cow Australian Veterinary Journal 44 304-308

Driancourt MA, Thatcher WW, Terqui M and Andrieu D (1991) Dynamics of ovarian follicular development in cattle during the estrous cycle, early pregnancy and in response to PMSG Domestic Animal Endocrinology 8 209-221

Dufour J, Whitmore HL, Ginther OJ and Casida LE (1972) Identification of the ovulatory follicle by its size on different days of the estrous cycle in heifers Journal of Animal Science 34 85-87

Erickson BH (1966) Development and radio-response of the prenatal bovine ovary Joumal of Reproduction and Fertility 11 97-105

Gallo GF and Block E (1989) Effect of recombinant bovine somatotropin (rbSt) on circulating concentrations of progesterone in plasma during estrous cycles and pregnancy in lactating dairy cows Journal of Animal Science 67 (Supplement 1) 345

Ginther OJ, Knopf L and Kastelic JP (1989) Temporal association among ovarian events in cattle during oestrous cycles with two and three follicular waves Journal of Reproduction and Fertility 87 223-230

Gong JG, Bramley T and Webb R (1991) The effect of recombinant bovine somatotropin on ovarian function in heifers: follicular populations and peripheral hormones Biology of Reproduction 45 941-949

Hart IC, Flux DS, Andrews P and McNeilly AS (1975) Radioimmunoassay for ovine and caprine growth hormone: its application to the measurement of basal circulating levels of growth hormone in the goat Hormone and Metabolism Research 7 35-40

Hodgen GD, Kenigsburg D, Collins RL and Schenken RS (1985) Selection of the dominant ovarian follicle and hormonal enhancement of the natural cycle. In In Vitro Fertilization and Embryo Transfer pp 23-37 Eds M Seppala and RG Edwards. NY Academy of Sciences, NY

Ireland JJ (1987) Control of follicular growth and development Journal of Reproduction and Fertility Supplement 34 39-54

Ireland JJ and Roche JF (1987) Hypotheses regarding development of dominant follicles during a bovine estrous cycle. In Follicular Growth and Ovulation Rate in Farm Animals pp 1-8 Eds JF Roche and D O'Callaghan. Martinus Nijhoff Publishers, Dordrecht

Kastelic JP, Ko JCH and Ginther OJ (1990) Suppression of dominant and subordinate ovarian follicles by a proteinaceous fraction of follicular fluid in heifers Theriogenology 34 499-509

Knopf L, Kastelic JP, Schallenberger E and Ginther OJ (1989) Ovarian follicular dynamics in heifers: test of two-wave hypothesis by ultrasonically monitoring individual follicles Domestic Animal Endocrinology 6 111-119

Langhout DJ, Spicer LJ and Geisert RD (1991) Development of a culture system for bovine granulosa cells: effects of growth hormone, estradiol, and gonadotropins on cell proliferation, steroidogenesis, and protein synthesis joumal of Animal Science 69 3321-3334

Law AS (1991) The Role of Follicular Fluid Proteins in the Control of Gonadotrophin Secretion and Follicular Development in the Heifer. PhD thesis, University of Edinburgh

Lovendahl P, Angus KB and Woolliams JA (1991) The effect of selection for milk yield on the response to growth hormone secretagogues in immature cattle Journal of Endocrinology 128 419-424

Marion GB, Gier HT and Choudray JB (1968) Micromorphology of the bovine ovarian follicular system Journal of Animal Science 27 451-465 
Osmond TJ, Carr WR, Hinks CJM, Land RB and Hill WG (1981) Physiological attributes as possible selection criteria for milk production: 2. Plasma insulin, triiodothyronine and thyroxine in bull Animal Production 32 159-163

Peters $H$, Byskov AG, Himmelstein-Braw $\mathbf{R}$ and Faber $\mathbf{M}$ (1975) Follicular growth: the basic event in the mouse and human ovary Joumal of Reproduction and Fertility 45 559-566

Pierson RA and Ginther OJ (1984) Ultrasonography of the bovine ovary Theriogenology 21 495-504

Pierson RA and Ginther OJ (1987a) Follicular populations during the estrous cycle in heifers. I. Influence of Day Animal Reproduction Science 14 165-176

Pierson RA and Ginther OJ (1987b) Reliability of diagnostic ultrasonography for identification and measurement of follicles and detecting the corpus luteum in heifers Theriogenology 28 929-936

Pierson RA and Ginther OJ (1988) Follicular populations during the estrous cycle in heifers. III. Time of selection of the ovulatory follicle Animal Reproduction Science 16 81-95

Pieterse MC, Taverne MAM, Kruip ThAM and Willemse AH (1990) Detection of corpora lutea and follicles in cows: a comparison of transvaginal ultrasonography and rectal palpation The Veterinary Record $126552-554$

Poretsky L and Kalin MF (1987) The gonadotropic function of insulin Endocrine Reviews 8 132-141

Price CA and Webb R (1988) Steroid control of gonadotropin secretion and ovarian function in heifers Endocrinology 122 2222-2231

Quirk SM, Hickey GJ and Fortune JE (1986) Growth and regression of ovarian follicles during the follicular phase of the oestrous cycle in heifers undergoing spontaneous and $\mathrm{PGF}_{2 a}$-induced luteolysis Journal of Reproduction and Fertility $77211-219$

Rajakoski E (1960) The ovarian follicular system in sexually mature heifers with special reference to seasonal, cyclical and left-right variations Acta Endocrinologica (Supplementum) 52 1-68

Savio JD, Keenan L, Boland MP and Roche JF (1988) Pattern of growth of dominant follicles during the oestrous cycle of heifers Journal of Reproduction and Fertility $83663-671$

Savion N, Lui GM, Laherty R and Gospodarowicz D (1981) Factors controlling proliferation and progesterone production by bovine granulosa cells in serum-free medium Endocrinology $109409-420$

Schemm SR, Deaver DR, Griel LC Jr and Muller LD (1990) Effect of recombinant bovine somatotropin on luteinizing hormone and ovarian function in lactating dairy cows Biology of Reproduction 42 815-821

Sirois J and Fortune JE (1988) Ovarian follicular dynamics during the estrous cycle in heifers monitored by real-time ultrasonography Biology of Reproduction 39 308-317

Vernon RG (1990) Influence of somatotropin on metabolism. In Use of Somatotropin in Livestock Production pp 31-50 Eds K Sejrsen, M Vestergaard and A Neimann-Sorensen. Elsevier Applied Science, London and New York

Webb R and McBride D (1991) Control of the proliferation of granulosa cells from small ovine follicles Journal of Reproduction and Fertility Supplement $\mathbf{4 3}$ $229-230$ 